Article

\title{
Self-Nanoemulsifying Drug Delivery Systems Containing Plantago lanceolata-An Assessment of Their Antioxidant and Antiinflammatory Effects
}

\author{
Azin Kalantari ${ }^{1}$, Dóra Kósa ${ }^{1}$, Dániel Nemes ${ }^{1}$, Zoltán Ujhelyi ${ }^{1}$, Pálma Fehér ${ }^{1}$, \\ Miklós Vecsernyés ${ }^{1}$, Judit Váradi ${ }^{1}$, Ferenc Fenyvesi ${ }^{1}$, Ákos Kuki ${ }^{2}$, Sándor Gonda ${ }^{3}$, \\ Gábor Vasas ${ }^{3}$, Rudolf Gesztelyi ${ }^{4}$, Anayatollah Salimi ${ }^{5}$ and Ildikó Bácskay ${ }^{1, *}$ \\ 1 Department of Pharmaceutical Technology (www.pharm.unideb.hu), University of Debrecen, \\ Nagyerdei körút 98, 4032 Debrecen, Hungary; azin.kalantari@pharm.unideb.hu (A.K.); \\ kdorik98@gmail.com (D.K.); nemes.daniel@pharm.unideb.hu (D.N.); ujhelyi.zoltan@pharm.unideb.hu (Z.U.); \\ feher.palma@pharm.unideb.hu (P.F.); vecsernyes.miklos@pharm.unideb.hu (M.V.); \\ varadi.judit@pharm.unideb.hu (J.V.); fenyvesi.ferenc@pharm.unideb.hu (F.F.) \\ 2 Department of Applied Chemistry (www.pharm.unideb.hu), University of Debrecen, Nagyerdei körút 98, \\ 4032 Debrecen, Hungary; kuki.akos@science.unideb.hu \\ 3 Department of Pharmacognosy (www.pharm.unideb.hu), University of Debrecen, Nagyerdei körút 98, \\ 4032 Debrecen, Hungary; gonda.sandor@science.unideb.hu (S.G.), vasas.gabor@pharm.unideb.hu (G.V.) \\ 4 Department of Pharmacology (www.med.unideb.hu), University of Debrecen, Nagyerdei körút 98, \\ 4032 Debrecen, Hungary; gesztelyi.rudolf@med.unideb.hu \\ 5 Nanotechnology Research Center, Ahvaz Jundishapur University of Medical Sciences, Ahvaz 61357-33184, \\ Iran; anayatsalimi2003@yahoo.com \\ * Correspondence: bacskay.ildiko@pharm.unideb.hu; Tel./Fax: +36-52-512-900 (ext. 54034)
}

Received: 16 August 2017; Accepted: 13 October 2017; Published: 20 October 2017

\begin{abstract}
The most important components of Plantago lanceolata L. leaves are catalpol, aucubin, and acteoside (=verbascoside). These bioactive compounds possess different pharmacological effects: anti-inflammatory, antioxidant, antineoplastic, and hepatoprotective. The aim of this study was to protect Plantago lanceolata extract from hydrolysis and to improve its antioxidant effect using self-nano-emulsifying drug delivery systems (SNEDDS). Eight SNEDDS compositions were prepared, and their physical properties, in vitro cytotoxicity, and in vivo AST / ALT values were investigated. MTT cell viability assay was performed on Caco- 2 cells. The well-diluted samples (200 to 1000 -fold dilutions) proved to be non-cytotoxic. The acute administration of PL-SNEDDS compositions resulted in minor changes in hepatic markers (AST, ALT), except for compositions 4 and $\mathbf{8}$ due to their high Transcutol contents $(80 \%)$. The non-toxic compositions showed a significant increase in free radical scavenger activity measured by the DPPH test compared to the blank SNEDDS. An indirect dissolution test was performed, based on the result of the DPPH antioxidant assay; the dissolution profiles of Plantago lancolata extract were statistically different from each SNEDDS. The anti-inflammatory effect of PL-SNEDDS compositions was confirmed by the ear inflammation test. For the complete examination period, all compositions decreased ear edema as compared to the positive (untreated) control. It can be concluded that PL-SNEDDS compositions could be used to deliver active natural compounds in a stable, efficient, and safe manner.
\end{abstract}

Keywords: SNEDDS; Plantago lanceolata; antioxidant and anti-inflammatory effects; DPPH test; cytotoxicity investigation; MTT-test; Caco-2 cells 


\section{Introduction}

Plantago is one of the most important genus within the Plantaginaceae family containing more than 200 species all around the world [1] Plantago lanceolata L. (Ribwort plantain) possesses various pharmacological properties for human health including antioxidant [2], anti-inflammatory [3], antineoplastic [4], hepatoprotective [5], immunoregulation, and neuroprotective properties, with an excellent and well-known safety profile. P. lanceolata has been also used in traditional medicine for its wound healing [6]. Its main active pharmaceutical ingredients belong to the group of phenylethanoid glycosides and iridoid glycosides [7]. Verbascoside (acteoside) is a phenylpropanoid glycoside and represents the main bioactive component of P. lanceolata [8]. The limitation of their formulations is their poor chemical stability due to hydrolysis [9]. The high hydrophilic character of verbascoside limits the range of possible applications. Stability studies have been reported about a greater stability of verbascoside in an $\mathrm{O} / \mathrm{W}$ emulsion [10]. Attention has been focused on the development of Self-Micro-Emulsifying Drug Delivery Systems (SMEDDS) in order to stabilize herbal drugs and to enhance their bioavailabilities [11]. Micro- and nanosized drug delivery systems containing herbal drugs have been considered as ideal carrier systems for the optimization of the activity/efficacy of these extracts and for the management of problems that have emerged that are associated with plant [12]. SNEDDS is frequently used for the stabilization of natural products and these carrier systems may also increase the bioavailability of natural bioactive materials [13]. P. lanceolata is one of the best-characterized and described Plantaginaceae species, which is official in the European Pharmacopoiea [14]. It has been reported as a safe and effective herb, but few toxicological studies have been established/carried out about the biocompatibility of PL herbal extracts in different carrier systems. The application of high doses or the exposure for long periods may result in mutagenic and cytotoxic effects [1]. Microemulsions and SNEDDS often require a high content of surfactants, which can lead to skin or mucosal irritation. Amphiphilic molecules can be ideal surfactants and co-surfactants in SNEDDS, but toxic effects must be screened to prove their harmlessness [15].

This study was conducted to develop SNEDDS containing Plantago lanceolata extract (PL-SNEDDS), to improve the physical stability of the herbal extract, and to increase its antiinflammatory and antioxidant effect. The components of PL-SNEDDS were Isopropyl-myristate, Transcutol, and Labrasol/Kolliphor RH 40. Ternary phase diagrams demonstrated the existing zones of nanoemulsions. Nevertheless, toxicity studies (MTT-viability test on Caco-2 cells, investigation of liver enzymes in mice) were also performed to certify the safety profile of developed formulations. The ear inflammation test and DPPH antioxidant test verified the effectiveness of SNEDDS compositions and verified the improved bioavailability of investigated formulations.

\section{Results}

\subsection{Bioactive Compounds in Plantago lancolata Leaves}

The concentrations of bioactive compounds found in the Plantaginis lanceolatae folium are presented in Table $1.10 \mathrm{mg} / \mathrm{mL}$ dry $\mathrm{MeOH}$ extract is equalent to $39.68 \mathrm{mg} \mathrm{DW} \mathrm{mL} / \mathrm{mL}$ plant drug. Acteoside is more hydrophilic than typical drug-like molecules (predicted $\log \mathrm{P}=0.82, \log \mathrm{D}=0.81$ at $\mathrm{pH} 7.50$ ). Iridoid glycosides are even more polar (predicted $\log \mathrm{P}=3.18$ and $=-3.43$ for aucubin and catalpol, respectively).

Table 1. Chemical description of Catalpol, Aucubin, and Acteoside in plantain (Plantago lanceolata).

\begin{tabular}{lll}
\hline & Catalpol (CA) & Aucubin (AU) \\
Chemical structures of \\
bioactive components
\end{tabular}




\subsection{Formulation and Evaluation of Self-Nano-Emulsifying Drug Delivery Systems}

Pseudoternary phase diagrams were constructed by using a conventional water titration technique. Isopropyl-myristate as oily phase, Labrasol or Kolliphor RH 40 as surfactant, and Transcutol HP as co-tenside were used in our compositions. The maximum nanoemulsion existing zones observed are shown in Figure 1. The distribution of droplet size is determined by dynamic light scattering (DLS) and presented in Figure 2. The developed SNEDDS-PL (shown in Table 2) spontaneously formed from nanoemulsion upon mild agitation in distillated water at room temperature. The concentration of P. lanceolata extract was $10 \mathrm{mg} / \mathrm{mL}$ in each composition. The investigated SNEDDS were stable for one month at room temperature. The screening of SNEDDS also involved the determination of the percentage of transmittance and the refractive index. The percentage of transmittance and refractive index of the resulted formulation were found to be $976.8 \pm 1.31 \%$ and $1.337 \pm 0.13 \%$, indicating the transparency of these formulations. Based on the result of these experiments, eight compositions were selected for further investigations.

Table 2. Compositions of Plantago lanceolata extract (PL-SNEDDS) (1-8). The components were Isopropyl myristate as oily phase, Labrasol or Kolliphor RH 40 as surfactant, and Transcutol HP as co-tenside. The concentration of Plantago lanceolata extract was $10 \mathrm{mg} / \mathrm{mL}$ in all samples.

\begin{tabular}{ccccc}
\hline Number of Compositions & Isopropyl-Myristate & Transcutol HP & Kolliphor RH 40 & Labrasol \\
\hline 1. & $33 \%$ & $33 \%$ & $33 \%$ & - \\
2. & $25 \%$ & $50 \%$ & $25 \%$ & - \\
3. & $15 \%$ & $60 \%$ & $15 \%$ & - \\
4. & $10 \%$ & $80 \%$ & $10 \%$ & - \\
5. & $33 \%$ & $33 \%$ & - & $33 \%$ \\
7. & $25 \%$ & $50 \%$ & - & $25 \%$ \\
8. & $15 \%$ & $60 \%$ & - & $15 \%$ \\
\hline
\end{tabular}
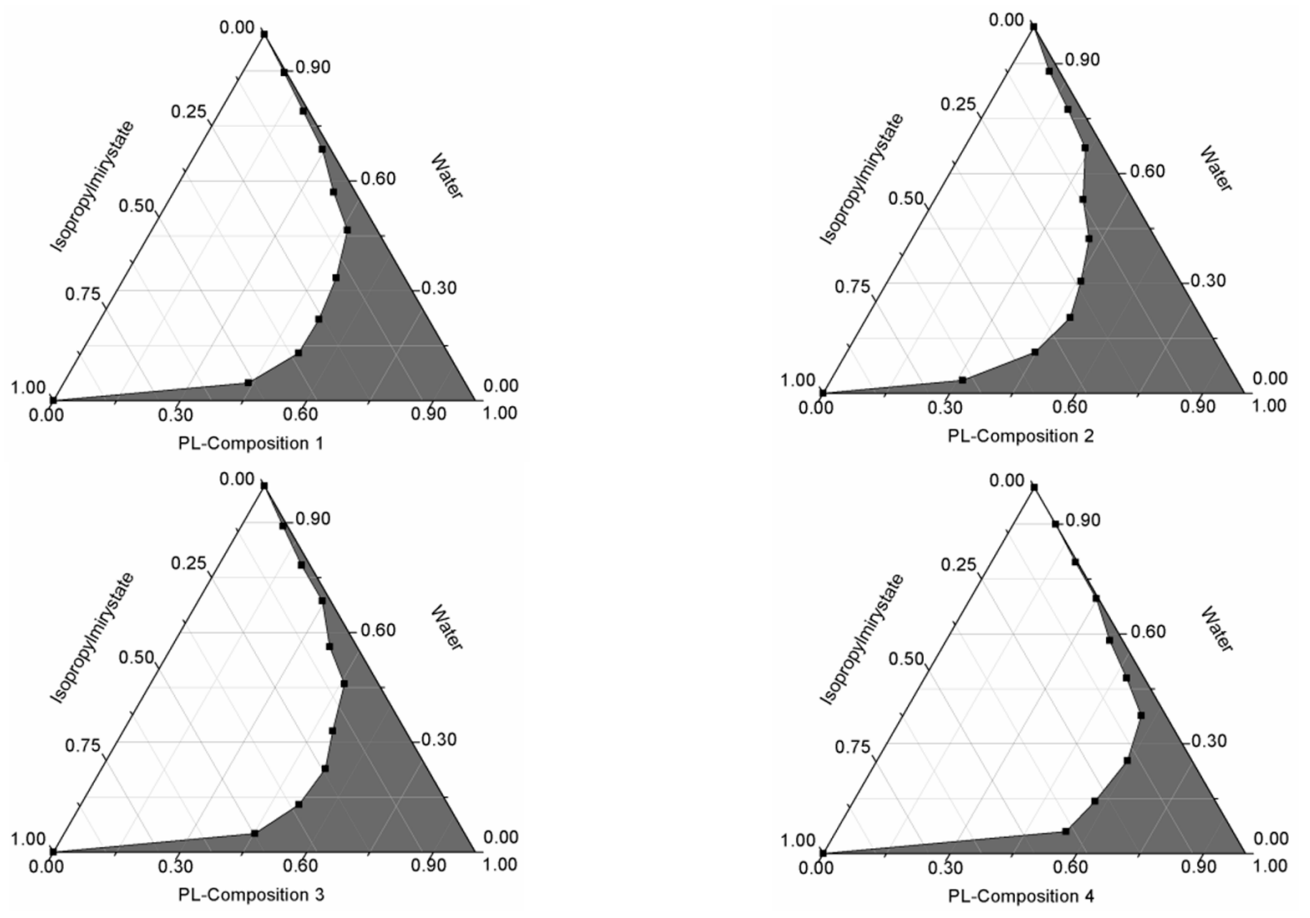

Figure 1. Cont. 

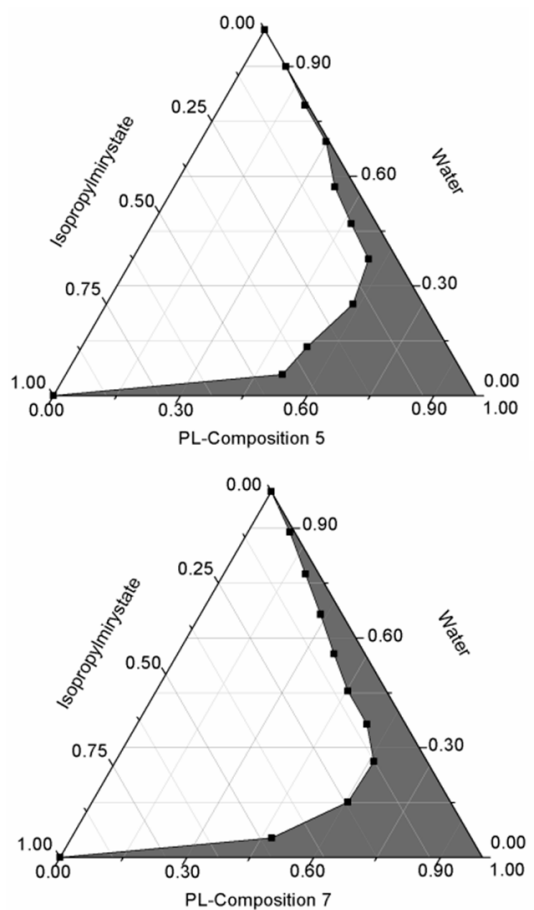
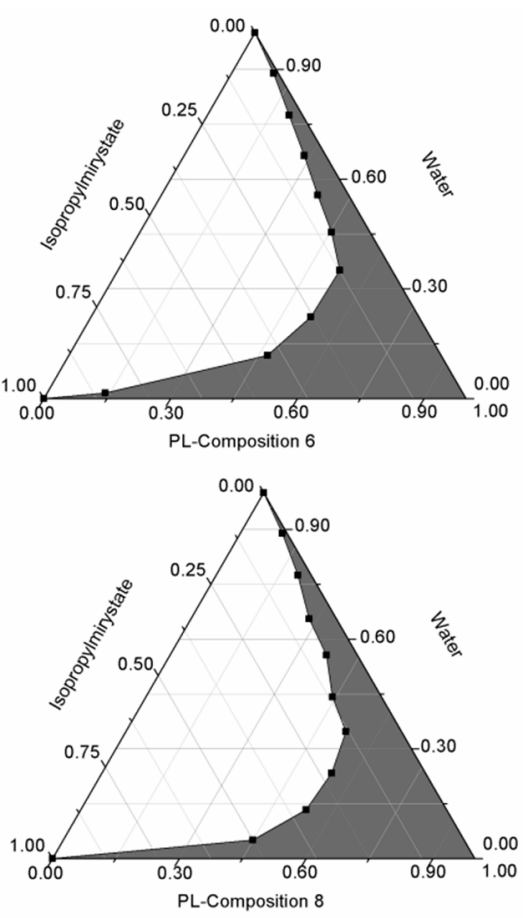

Figure 1. Pseudoternary phase diagrams of compositions 1-8. (Shaded areas represented nanoemulsions).

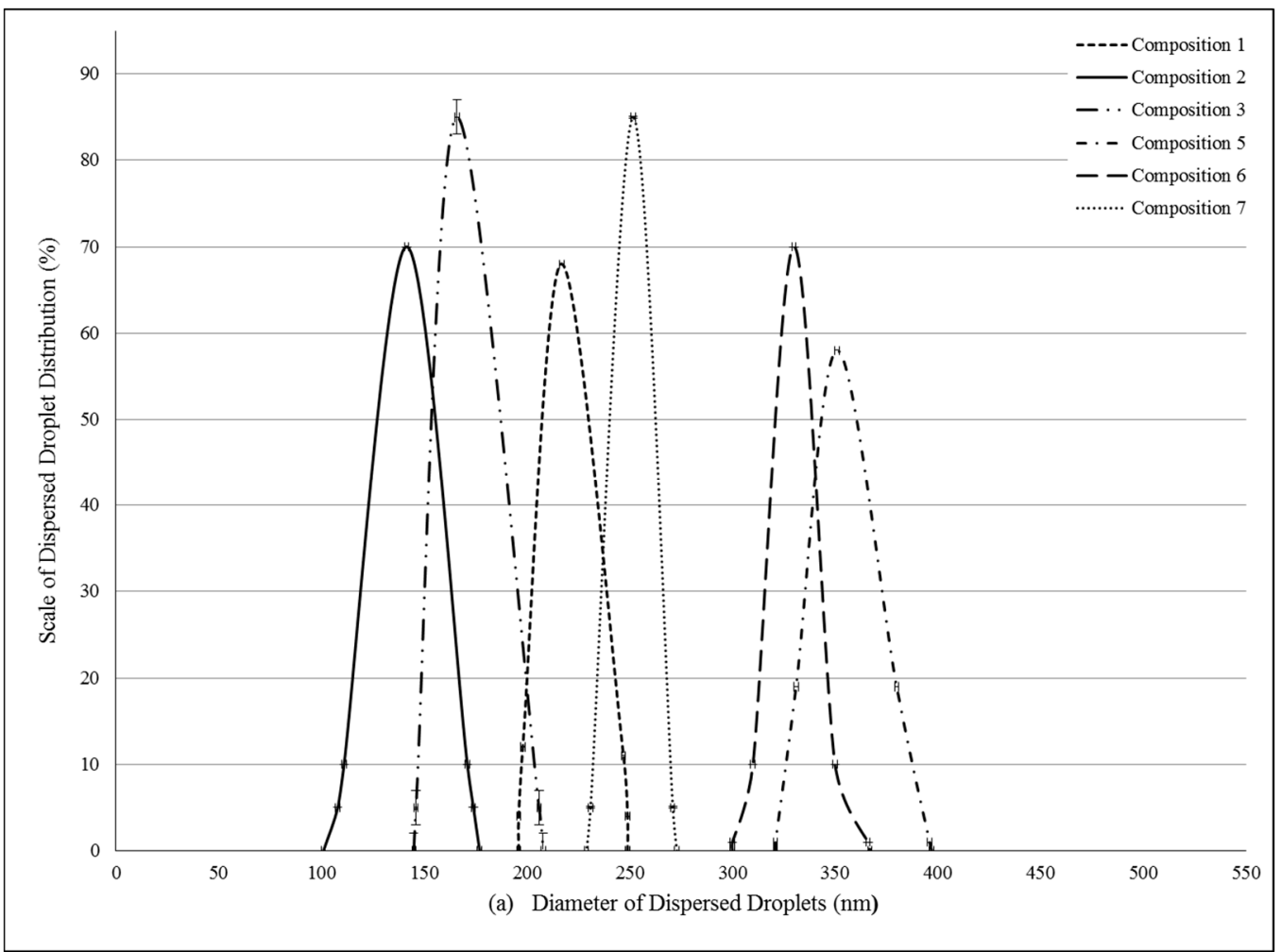

Figure 2. Cont. 


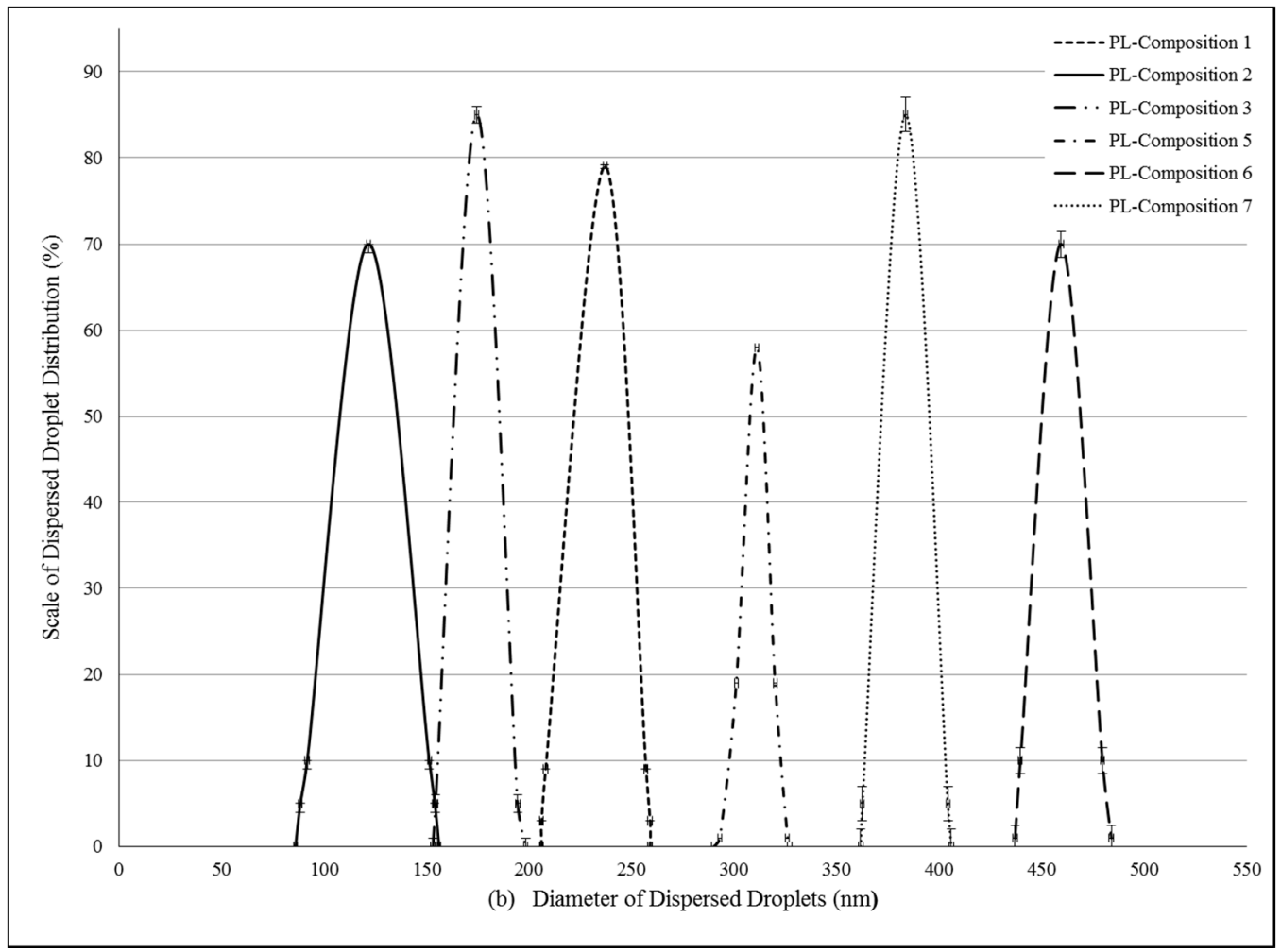

Figure 2. (a) Evaluated droplet size of self-nano-emulsifying drug delivery systems (SNEDDS) in water via dynamic light scattering (DLS) measurement. Evaluated average droplet sizes: composition 1: $233.62 \pm 2.34 \mathrm{~nm}$, composition 2: $141.51 \pm 1.25 \mathrm{~nm}$, composition 3: $166.44 \pm 1.05 \mathrm{~nm}$, composition 5: $374.89 \pm 0.23 \mathrm{~nm}$, composition 6: $330.28 \pm 0.95 \mathrm{~nm}$, composition 7: $251.81 \pm 1.95 \mathrm{~nm}$. Values are expressed as means $\pm \mathrm{SD}, n=5$; (b) Evaluated droplet size of self-nano-emulsifying drug delivery systems (SNEDDS) in water via dynamic light scattering (DLS) measurement. Evaluated average droplet sizes: PL-composition 1: $245.32 \pm 0.64 \mathrm{~nm}$, PL-composition 2: $121.75 \pm 1.00$ nm, PL-composition 3: $174.50 \pm 1.00 \mathrm{~nm}$, PL-composition 5: $313.02 \pm 3.12 \mathrm{~nm}$, PL-composition 6: $459.50 \pm 3.85 \mathrm{~nm}$, PL-composition 7: $383.20 \pm 2.55 \mathrm{~nm}$. Values are expressed as means $\pm \mathrm{SD}, n=5$.

\subsection{Stability Studies of Self-Nano-Emulsifying Drug Delivery Systems}

The level P. lanceolata extract in SNEDDS remained more than $90 \%$ at day 10 in condition of $40{ }^{\circ} \mathrm{C}$; relative humidity was $92.5 \%$. While the temperature was increased to $60^{\circ} \mathrm{C}$, the level of herbal drug extract was decreased to $91.6 \%$. These data suggested that SNEDDS is stable under the condition of high temperature and high humidity. Glycosides of Plantago species have a $\mathrm{pH}$-dependent stability. While iridoids spontaneously decompose at very low $\mathrm{pH}$ (base of the Trim-Hill assay), acteoside becomes unstable at $\mathrm{pH} 7$ and above. The original $\mathrm{pH}$ of the mixture (typically around $\mathrm{pH} 5-6$ ) maintains stability of major compounds to an acceptable extent. This means that the extraction environment is "buffered" by the plant components and hence preserves most compounds during liquid extraction. The decomposing enzyme of iridoid glycosides (beta-glucosidase) is unable to operate in $\mathrm{MeOH}$ and, additionally, is inactivated by the heat.

\subsection{Toxicity Investigations}

\subsubsection{MTT Viability Assay on Caco-2 Cell Monolayers}

MTT cell viability assay was performed on Caco-2 cells. (Figure 3a,b) Compositions $\mathbf{1}-\mathbf{8}$ were diluted by Hank's balanced solution (HBSS). $1 \mathrm{mg}$ PL-SNEDDS composition was diluted by 1-1000 mL HBSS. There was a linear relationship between the cytotoxicity and the ratio of dilution of different 
SNEDDS compositions. The more concentrated samples decreased the cell viability and resulted in significant cytotoxicity. The higher the ratio of dilution of SNEDDS compositions, the better the cell viability of the Caco-2 cell line was. Application of those compositions (compositions 1, 2 and 5, 6), in which the content of Transcutol HP was lower, resulted in higher cell viability values than in the cases of compositions 3, 4 and 7, 8, where the range of Transcutol content was $60-80 \%$. Nevertheless, it can be observed that there is a reduced cytotoxicity at a dilution of 200-1000. Significant differences between groups for compositions 1, 2, 5, 6 and groups for compositions 3, 4, 7, 8 (with the exception of composition 3 vs. compositions 5 and 6 at 100 dilution ratio, where the differences did not reach level of statistical significance). There are significant differences between PL-Composition-treated groups and positive or negative controls. After regression analysis, it seems that there are significant differences between groups for compositions 1, 2, 5, $\mathbf{6}$ and groups for compositions 3, 4, 7, 8 (Table 3).

Table 3. Regression parameters using cuboid polynomial equation and goodness of fit data for the cell viability evaluation following MTT (3-(4,5-dimethylthiazol-2-yl)-2,5-diphenyltetrazolium bromide) assay on Caco-2 cells treated with compositions 1-8 (see: Figure 3, Panel B). SE = Standard Error. (Comp. = Composition).

\begin{tabular}{ccccccccc}
\hline & Comp. 1 & Comp. 2 & Comp. 3 & Comp. 4 & Comp. 5 & Comp. 6 & Comp. 7 & Comp. 8 \\
\hline B0 & 59.16 & 55.65 & 47.21 & 39.53 & 57.13 & 57.72 & 44.76 \\
B1 & 0.1483 & 0.1551 & 0.1984 & 0.2363 & 0.15 & 0.1353 & 0.187 \\
B2 & $-2.793 \times 10^{-4}$ & $-2.73 \times 10^{-4}$ & $-3.577 \times 10^{-4}$ & $-4.222 \times 10^{-4}$ & $-2.848 \times 10^{-4}$ & $-2.477 \times 10^{-4}$ & $-3.303 \times 10^{-4}$ & $-4.08 \times 10^{-4}$ \\
B3 & $1.738 \times 10^{-7}$ & $1.631 \times 10^{-7}$ & $2.092 \times 10^{-7}$ & $2.414 \times 10^{-7}$ & $1.783 \times 10^{-7}$ & $1.541 \times 10^{-7}$ & $1.924 \times 10^{-7}$ & $2.366 \times 10^{-7}$ \\
B0 SE & 1.42 & 1.283 & 1.766 & 1.771 & 1.43 & 1.283 & 1.752 & 1.627 \\
B1 SE & $1.785 \times 10^{-2}$ & $1.613 \times 10^{-2}$ & $2.22 \times 10^{-2}$ & $2.226 \times 10^{-2}$ & $1.798 \times 10^{-2}$ & $1.613 \times 10^{-2}$ & $2.202 \times 10^{-2}$ & $2.045 \times 10^{-2}$ \\
B2 SE & $4.45 \times 10^{-5}$ & $4.022 \times 10^{-5}$ & $5.535 \times 10^{-5}$ & $5.551 \times 10^{-5}$ & $4.483 \times 10^{-5}$ & $4.022 \times 10^{-5}$ & $5.49 \times 10^{-5}$ & $5.1 \times 10^{-5}$ \\
B3 SE & $2.916 \times 10^{-8}$ & $2.635 \times 10^{-8}$ & $3.627 \times 10^{-8}$ & $3.637 \times 10^{-8}$ & $2.937 \times 10^{-8}$ & $2.635 \times 10^{-8}$ & $3.597 \times 10^{-8}$ & $3.341 \times 10^{-8}$ \\
R $^{\mathbf{2}}$ & 0.9296 & 0.9501 & 0.9252 & 0.9399 & 0.9301 & 0.94 & 0.925 \\
\hline
\end{tabular}

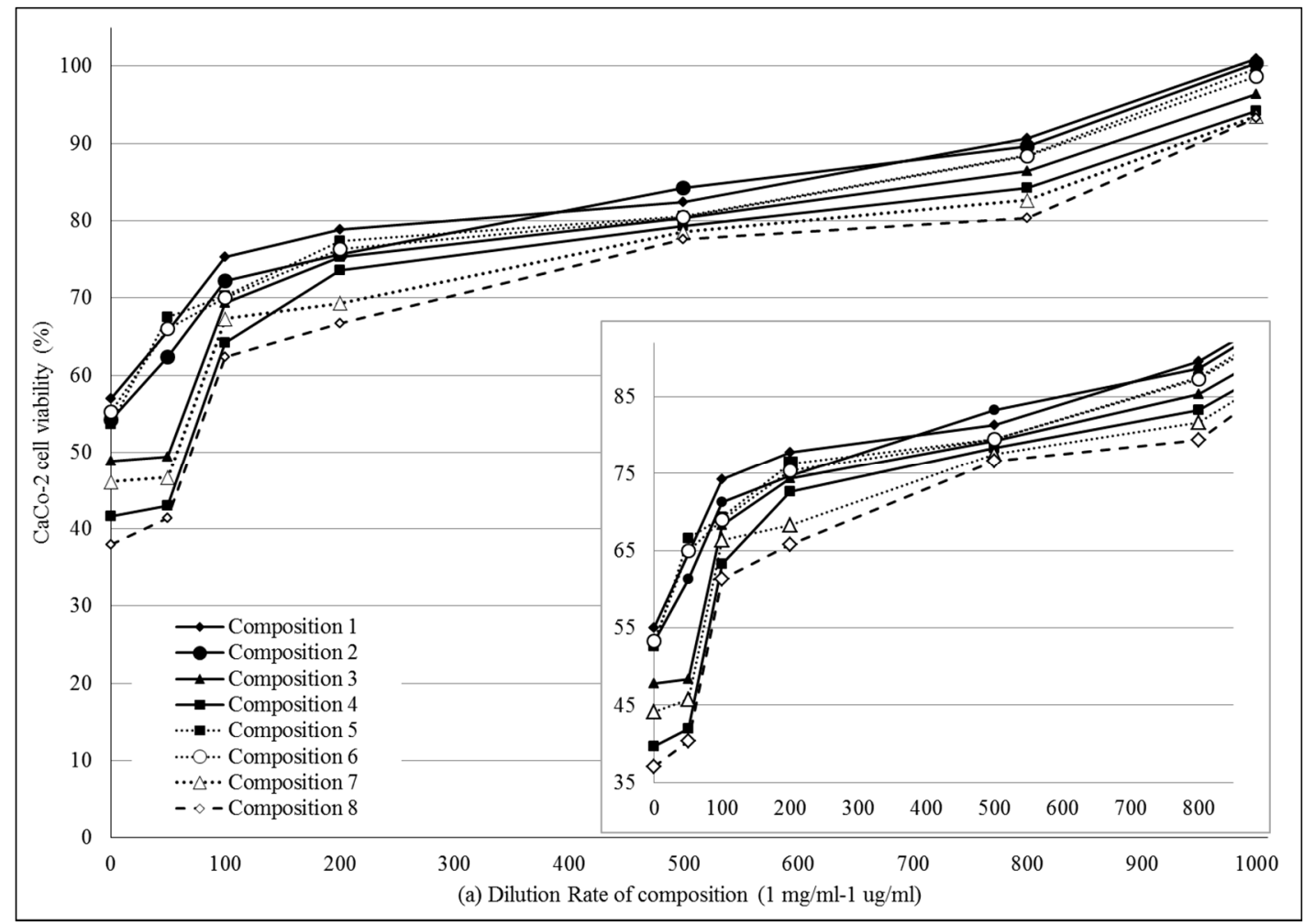

Figure 3. Cont. 


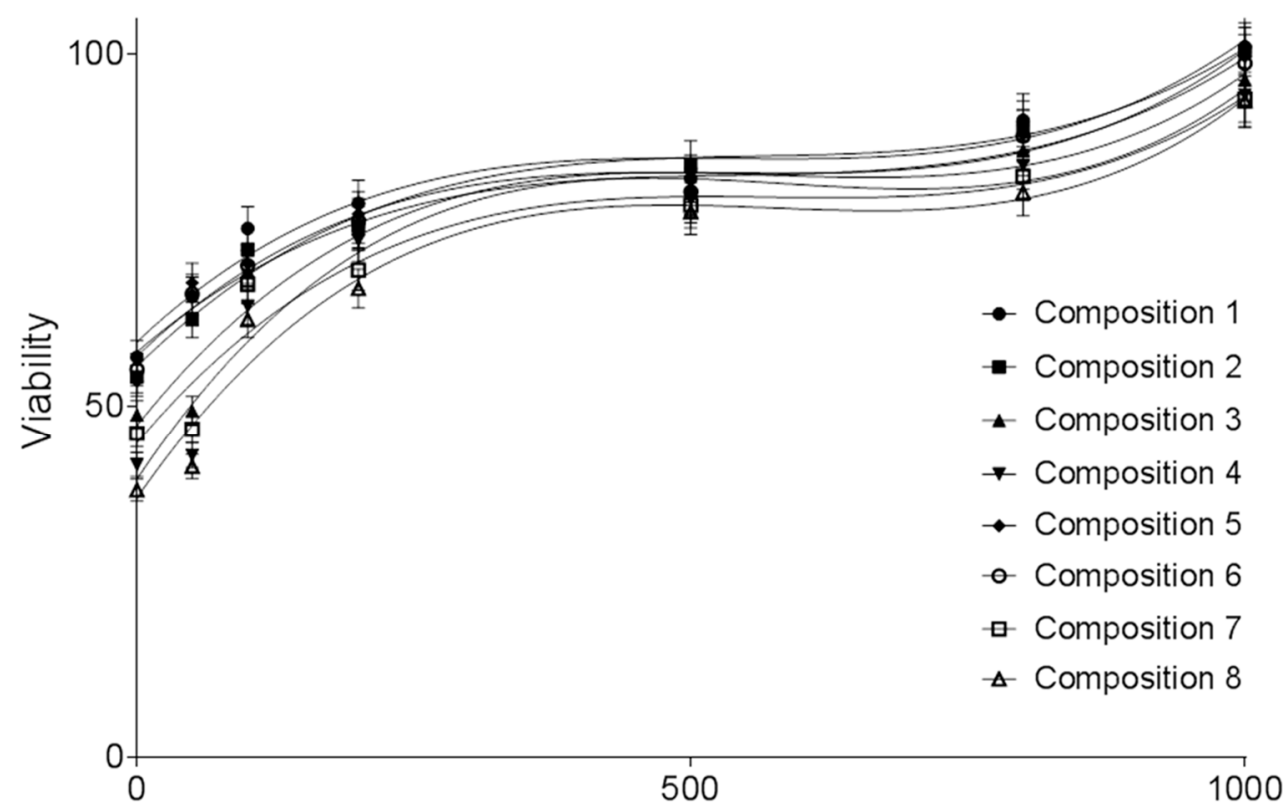

(b) Dilution

Figure 3. (a) Cell viability evaluation following MTT assay on Caco-2 cells treated with compositions 1-8 in the function of dilution ratio. $1 \mathrm{mg}$ PL-SNEDDS composition was diluted by 1-1000 mL HBSS. Each data point represents the mean \pm S.D., $n=10$. Significant differences between groups for compositions 1, 2, 5, 6 and groups for compositions 3, 4, 7, 8 are marked with an asterisk (with the exception of composition 3 vs. compositions 5 and $\mathbf{6}$ at 100 dilution ratio, where the differences did not reach level of statistical significance). Positive control was Triton-X-treated group, negative control was Hank's balanced solution (HBSS)-treated group; (b) Cell viability evaluation following MTT assay on Caco-2 cells treated with compositions 1-8 in the function of dilution ratio. $1 \mathrm{mg}$ PL-SNEDDS composition was diluted by 1-1000 mL HBSS. Each data point represents the mean \pm S.D., $n=10$. Significant differences between groups for compositions 1, 2, 5, 6 and groups for compositions 3, 4, 7, 8 are marked with an asterisk (with the exception of composition 3 vs. compositions 5 and 6 at 100 dilution ratio, where the differences did not reach level of statistical significance). Positive control was Triton-X-treated group, negative control was Hank's balanced solution (HBSS)-treated group. Linear regression of cell viability curves presented in the Figure 3a (regression parameters and goodness of fit data shown in Table 3).

\subsubsection{Effect of PL-SNEDDS on Hepatic Function Markers}

Effect of all SNEDDS compositions containing P. lanceolata on hepatic function markers was investigated. Table 4 shows the effect of orally administrated SNEDDS-PL on liver function enzymes AST and ALT after 2 days of treatment. Composition 4 and 8, containing $80 \%$ of Transcutol HP, resulted in fatal consequence, and number of dead mice were $5 / 5$ and $4 / 5$, respectively. These samples were removed from our experimental design. However, those compositions (SNEDDS-PL 1, 2, 3 and 5, 6, 7), in which the range of Transcutol HP content altered between 33-60\%, did not show significant increase in AST. Significant decrease of AST enzyme levels were observed. However, the changing of ALT enzyme level was not significant in each case. Moderate rise in ALT was recorded as compared with the normal control group. The results revealed that our samples excluding Compositions $\mathbf{4}$ and $\mathbf{8}$ may be safely applicable in our further experiments. 
Table 4. Effect of SNEDDS containing P. lanceolata extract on serum AST and ALT enzyme activities. Each value represents the means \pm SD for 6 mice and is expressed in IU/L or U/L. Groups treated with the compositions 1-8 were compared to the control group, significant differences were marked with an asterisk. Administration of compositions $\mathbf{4}$ and $\mathbf{8}$ resulted in the death of mice within 2 days (ND = No Data), (Comp. = Composition).

\begin{tabular}{cccccccccc}
\hline & Control & Comp. 1 & Comp. 2 & Comp. 3 & Comp. 4 & Comp. 5 & Comp. 6 & Comp. 7 & Comp. 8 \\
\hline AST (IU/L) & $362.28 \pm 12.3$ & $183.6 \pm 34^{*}$ & $225.78 \pm 13.4^{*}$ & $285.90 \pm 12.3^{*}$ & ND & $232.56 \pm 10.6^{*}$ & $214.6 \pm 12.3^{*}$ & $298.78 \pm 33.2^{*}$ & ND \\
ALT (U/L) & $92.34 \pm 23.4$ & $113.23 \pm 42.1$ & $98.70 \pm 29.7$ & $145.62 \pm 38.6^{*}$ & ND & $93.4 \pm 21.4$ & $119.21 \pm 13.2$ & $138.23 \pm 12.6^{*}$ & ND \\
\hline
\end{tabular}

\subsection{In Vitro Dissolution Study}

In vitro release profiles of SNEDDS were investigated by the determination of antioxidant capacity of diffused samples. (Figure 4a,b, Table 5). Negative control was Plantago lanceolate extract without SNEDDS. All PL-Composition-treated groups differed significantly from the negative control group (no mark is shown).The DPPH inhibition of dissolved herb extract was significantly different from $15 \mathrm{~min}$ to $60 \mathrm{~min}$. After $15 \mathrm{~min}$, when the hard gelatin capsules were disintegrated, the SNEDDS formed nanoemulsion droplets rapidly and the antioxidant capacity of PL-Compositions was sharply increased. The antioxidant abilities of PL-Composition $\mathbf{2}$ and $\mathbf{6}$ were significantly higher than the other PL-Compositions. Based on the the DPPH antioxidant assay, the dissolution profiles of P. lancolata extract were statistically different from each SNEDDS. The efficacy of diffusion of PL-SNEDDS compositions were 4-5 fold higher than the extract alone.

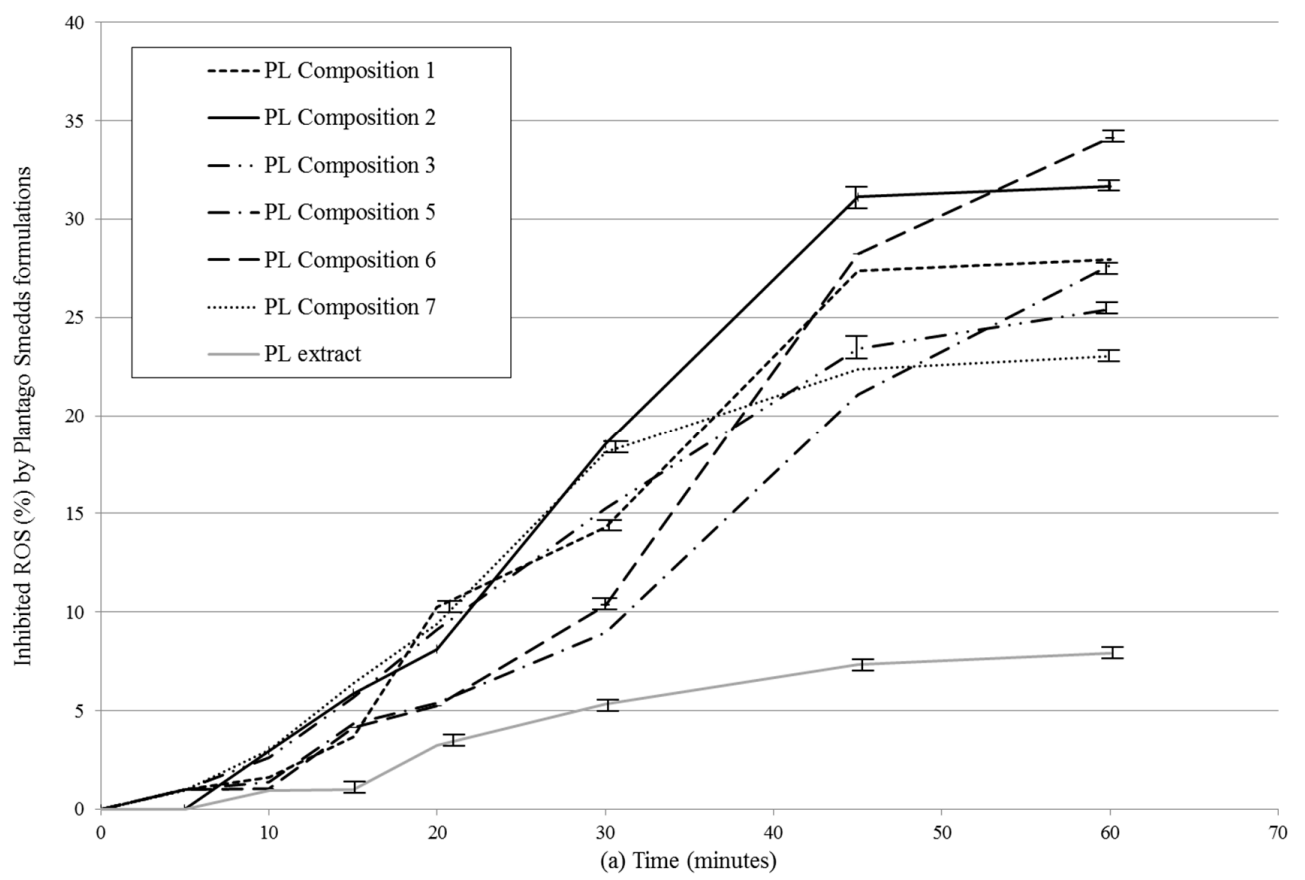

Figure 4. Cont. 


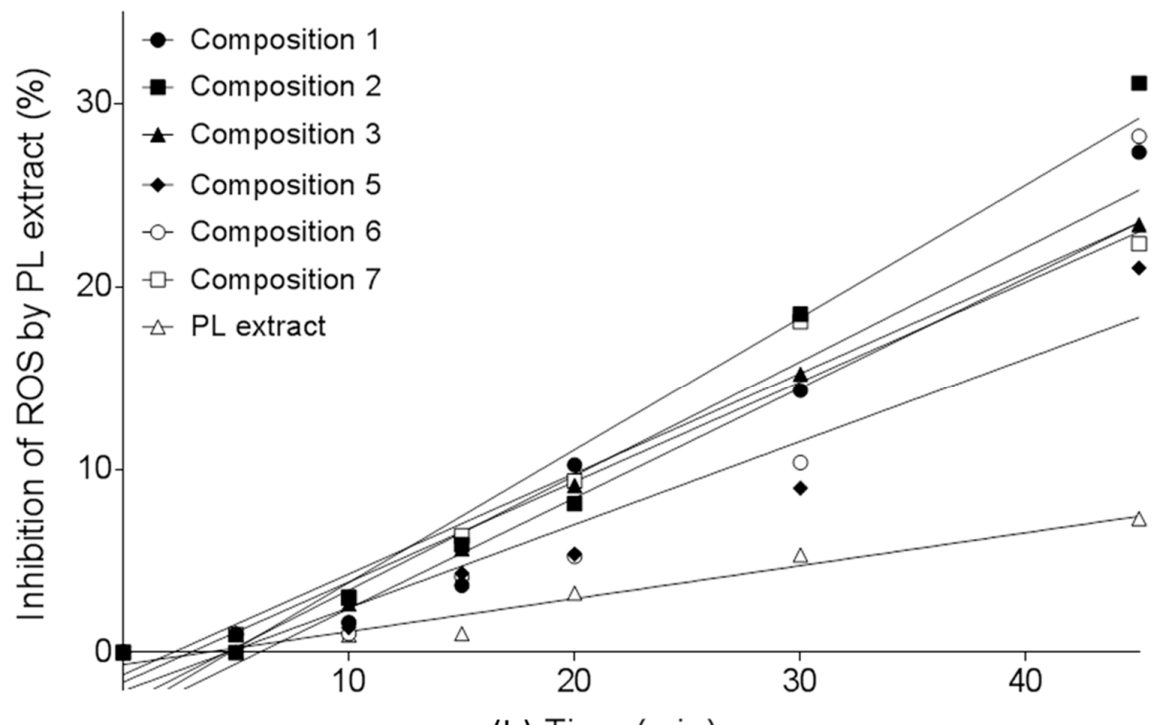

(b) Time (min)

Figure 4. (a) In vitro dissolution study of PL-SNEDDS compositions based on the determination of DPPH (2,2-diphenyl-1-picrylhydrazyl) radical scavenging activity. Values are expressed as means $\pm \mathrm{SD}, n=5$. Negative control was Plantago lanceolata extract without SNEDDS. All PL-composition-treated groups differed significantly from the negative control group (no mark is shown); (b) In vitro dissolution study of PL-SNEDDS compositions based on the determination of DPPH (2,2-diphenyl-1-picrylhydrazyl) radical scavenging activity. Values are expressed as means \pm SD, $n=5$. Negative control was Plantago lanceolata extract without SNEDDS. All PL-composition-treated groups differed significantly from the negative control group (no mark is shown). Linear regression of inhibition curves presented in Figure 4a. A (regression parameters and goodness of fit data shown in Table 5). As reactive oxidative species (ROS) inhibition data belonging to $60 \mathrm{~min}$ obviously deviate from linearity (to the same direction), they were omitted from this analysis.

Table 5. Regression parameters and goodness of fit data for the in vitro dissolution study of PL-SNEDDS compositions based on the determination of DPPH radical scavenging activity (see: Figure $5 b) . \mathrm{SE}=$ Standard Error, (Comp. = Composition).

\begin{tabular}{cccccccc}
\hline & Comp. 1 & Comp. 2 & Comp. 3 & Comp. 5 & Comp. 6 & Comp. 7 & PL Extract \\
\hline Slope & 0.625 & 0.725 & 0.548 & 0.454 & 0.604 & 0.549 & 0.18 \\
$( \pm$ SE $)$ & $( \pm 0.061)$ & $( \pm 0.061)$ & $( \pm 0.027)$ & $( \pm 0.056)$ & $( \pm 0.098)$ & $( \pm 0.043)$ & $( \pm 0.017)$ \\
Y-intercept & -2.849 & -3.436 & -1.632 & -2.108 & -3.635 & -1.213 & -0.662 \\
$( \pm$ SE $)$ & $( \pm 1.408)$ & $( \pm 1.415)$ & $( \pm 0.627)$ & $( \pm 1.292)$ & $( \pm 2.235)$ & $( \pm 0.988)$ & $( \pm 0.382)$ \\
X-intercept & 4.556 & 4.737 & 2.979 & 4.638 & 6.023 & 2.207 & 3.677 \\
$\mathrm{R}^{2}$ & 0.954 & 0.9651 & 0.9877 & 0.9286 & 0.8844 & 0.9702 & 0.9588 \\
\hline
\end{tabular}

\subsection{DPPH Radical Scavenging Activity of SNEDDS-PL Samples}

The DPPH antioxidant assay is based on the ability of a stable free radical (DPPH) to change color in the presence of antioxidants. In our antioxidant capacity measurements, compositions 1-3 and 5-7, with or without $P$. lanceolata extracts, were tested. As controls the appropriate blank compositions (compositions 1-3 and 5-7) were applied. Each sample contained $10 \mathrm{mg} / \mathrm{mL}$ P. lanceolata extract (PL-composition). The percentage of antioxidant activity (AA \%) of each substance was assessed by DPPH free radical assay. The measurement of the DPPH radical scavenging activity was performed according to methodology described by Brand-Williams et al. [16]. There were significant differences between PL-composition treated groups and compositions without PL and PL-composition treated groups and PL-E treated sample (as positive control). These significant differences between PL-composition groups and the positive control group have been marked with an asterisk. 


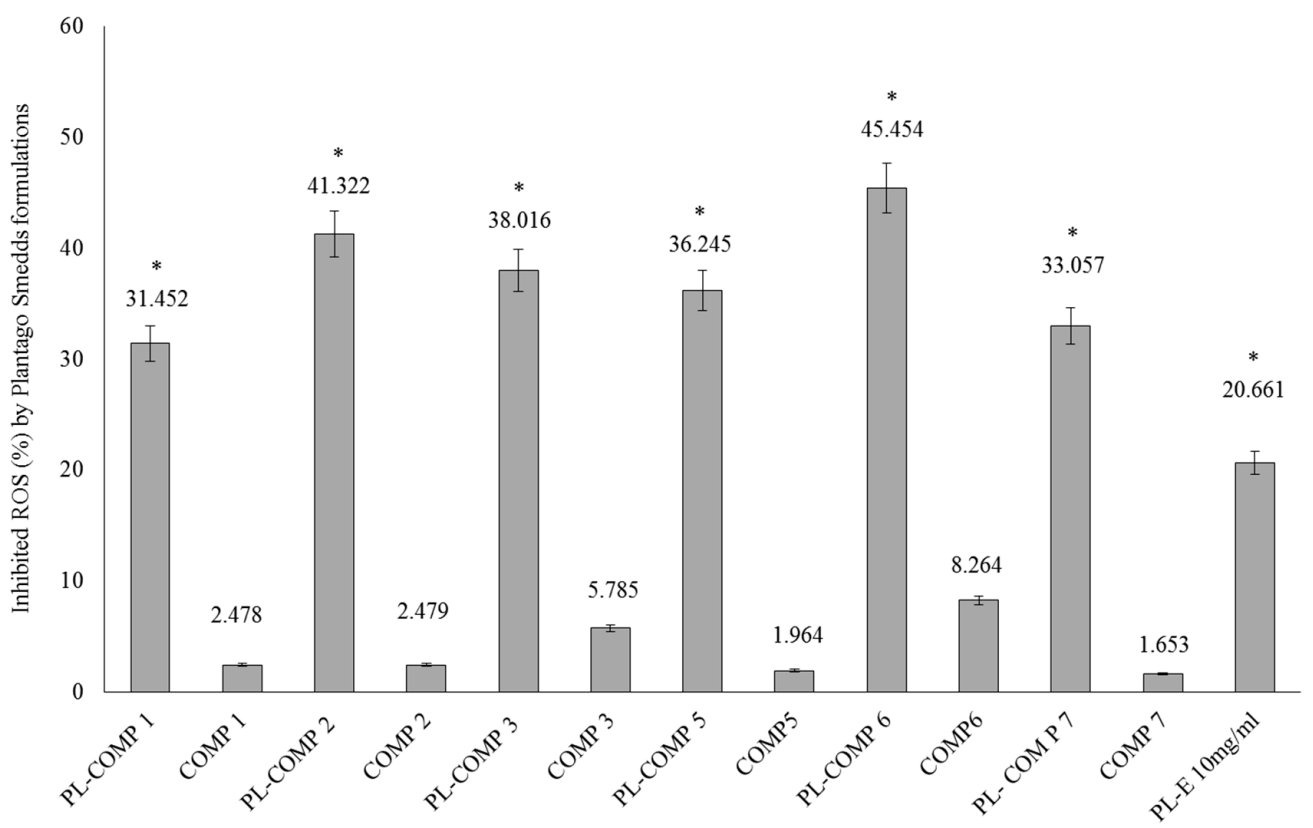

Figure 5. Inhibition of (ROS, \%) by different PL-compositions. The positive control was P. lanceolata extract in a concentration $10 \mathrm{mg} / \mathrm{mL}$. The negative controls were the compositions without $P$. lanceolata extract. Values are expressed as means $\pm \mathrm{SD}, n=5$. Significant differences between PL-composition groups and the positive control group have been marked with an asterisk.

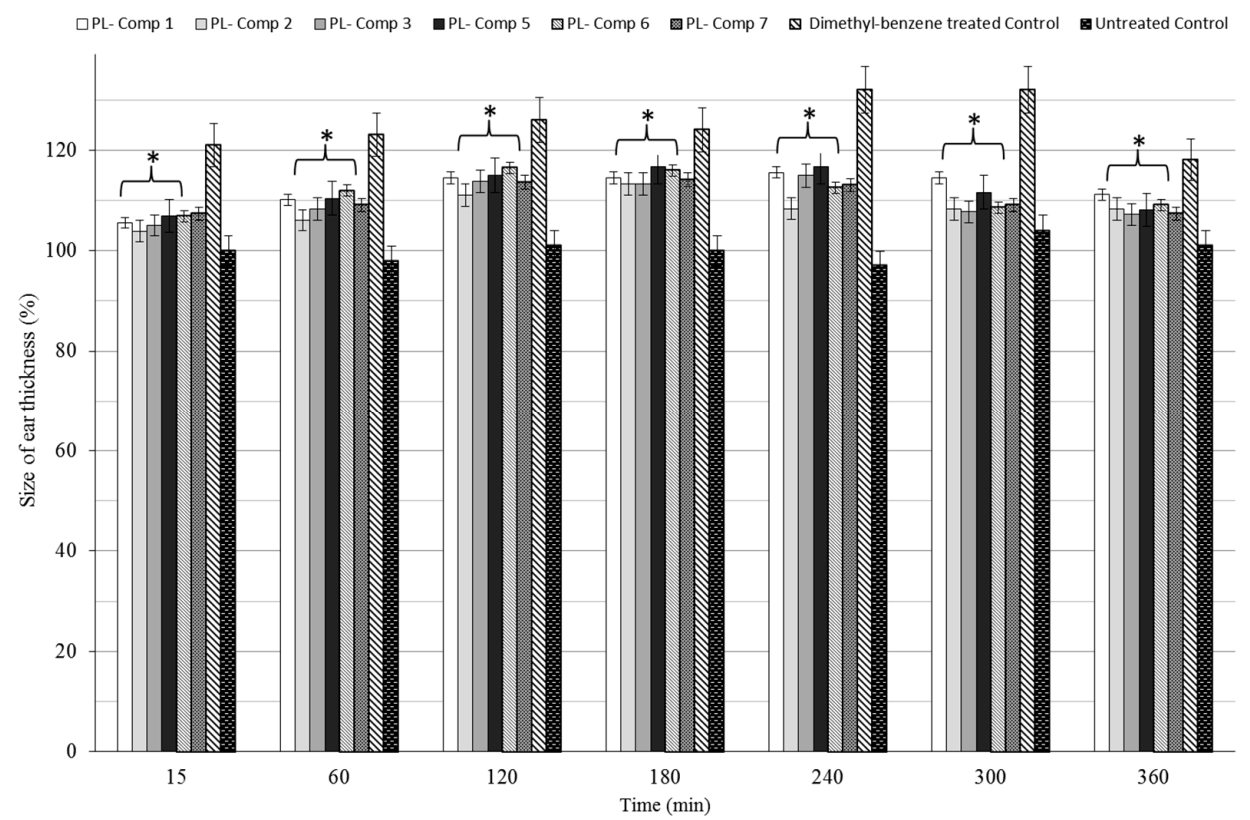

Figure 6. Time revolution of baseline corrected ear thickness $(\mu \mathrm{m})$ in terms of different SNEDDS compositions containing $10 \mathrm{mg} / \mathrm{mL}$ P. lanceolata extract in a dimethyl-benzene-induced ear edema model in mice. The administered extract dose was $150 \mathrm{mg} / \mathrm{kg} /$ day formulated in SNEDDS and administered by gavage. For the complete time period, compositions showed significant differences to the positive control. As positive control, mice were treated with dimethyl-benzene without PL-SNEDDS pre-treatment, while in the negative control group, the mice received no treatment. Values are expressed as means $\pm \mathrm{SD}, n=6$. All groups receiving a treatment with PL-components 1-3, 5-7 differed significantly from their positive control group. Asterisk shown these significant differences. 
It has been demonstrated that all compositions were able to significantly inhibit DPPH mean oxidation. From PL-compositions, PL-composition $\mathbf{6}$ showed the most effective antioxidant activity in the DPPH assay. According to our measurements, PL-composition 7 showed the smallest activity, although its antioxidant capacity was found to be significantly higher than non-formulated P. lanceolata extract (PL-E).

\subsection{Dimethyl-Benzene-Induced Ear Edema}

Every orally-administered composition containing $10 \mathrm{mg} / \mathrm{mL}$ P. lanceolata extract significantly decreased ear thickness in the complete time period compared to positive control (dimethyl-benzene only), as seen in Figure 6. The maximum effect of dimethyl-benzene was measured at $2 \mathrm{~h}$ post-challenge time in either case. For the complete examination period, all compositions decrease ear edema as compared to the positive (untreated) control.

\section{Discussion}

P. lanceolata is a well-known species which exhibits various pharmacological effects [17]. However, the high capability of its bioactive components for hydrolysis resulted in poor stability of this natural extract [18]. Vertuani et al. [10] found $90 \%$ decrease of acteosid level at $40{ }^{\circ} \mathrm{C}$ and $\mathrm{pH}=7$, and $80 \%$ at $\mathrm{pH}=6$. In our study, we showed that self-nano-emulsifying drug delivery systems (SNEDDS) can be feasible solution to improve the stability of active pharmaceutical ingredients (APIs) of P. lanceolata extract. Liposomes for parenteral administration can also ameliorate the stability of verbascoside by preventing its hydrolysis [9]. Nevertheless, nanoemulsions may increase the stability of natural compounds and encapsulation improves the antioxidant activity of APIs [19]. It is worth noting that our PL-SNEDDS compositions potentiated the free radical scavenging activity of $P$. lanceolata extract compared to positive control (non-encapsulated P. lanceolata extract). DPPH reduction assay was an efficient and rapid method to screen the scavenger activity of PL-SNEDDS samples in vitro [20]. DPPH reaction is predictive but not sufficient to certify the therapeutic potential of P. lanceolata extract [19]. Therefore, ear inflammation test was carried out. Dimethyl-benzene is capable of inducing ear edema in the proper dose, as described earlier [21]; every PL-SNEDDS composition was able to decrease the dimethyl-benzene-induced inflammation. The $n$-hexane insoluble fraction of Plantago lanceolate demonstrated anti-inflammatory activities in mice. The fraction reduced the volume of paw edema and COX-2 expression as well [22].

Based on the predictive value of DPPH test, indirect dissolution test was developed. Those PL-SNEDDS compositions, which contain 25-25\% Isopropyl-myristate-Kolliphor RH 40/Labrasol and 50\% Transcutol HP, resulted in higher reduction of free radicals. According to the result of dissolution and ear inflammation tests, the ranking of PL-SNEDDS compositions was the same in the case of both tests. It is supported by Li et al. [23] experiment that stable SNEDDS-persimmon leaf extract formulations were prepared and linear in vitro-in vivo correlation was observed. Lipid-based nanosystems are also enable to increase the bioavailability of APIs, and hence more effective formulations can be developed [24]. The degree of efficacy depends on the types of oil, surfactant, and co-surfactant in these nano-emulsifying systems [25]. In our formulation, Transcutol HP as co-tenside was an effective penetration enhancer [26], isopropyl-myristate, as the oily phase, could dissolve the more lipophilic components of P. lanceolata [27], and Kolliphor RH 40/Labrasol was able to enhance the paracellular permeability of APIs on Caco-2 cell monolayer and was suitable to stabilize the most hydrophilic component of natural compounds [15,28]. Amphiphilic molecules can be ideal surfactants and co-surfactants in microemulsions [25], but cytocompatibility screening can support assess their toxicity profile. For this reason, in vitro MTT cell viability test was made and in vivo AST / ALT values were investigated in mice. In acute toxicity study the diluted PL-SNEDDS compositions was more concentrated than in cytotoxicity experiment on Caco- 2 cells. However, the higher was the dilution, the safer were the compositions. The well diluted samples (200 to 1000-folds dilution) proved to be non-cytotoxic. These data are important to assess the toxicity profile of our 
compositions, but there are some limitations of investigations. Caco-2 cells are used extensively as an in vitro model for the rapid screening of intestinal absorption and cytotoxicity [29,30]. In vitro assay can predict irritancy, potential, and delayed toxicity of surfactants [31], but if it were complemented with different in vivo tests (i.e., determination of hepatic function markers, i.e., in animal experiments) then it could be more predictive. The toxicity ranking of PL-SNEDDS compositions was the same in both tests except for PL-SNEDDS compositions 4 and 8 . Because these samples resulted in the death of mice. It might indicate that the MTT cytotoxicity test is not appropriate to assess overall toxicity. More than one assay on different cell lines complemented with in vivo animal toxicity studies are applicable to determine the toxicity profile of compositions. Nevertheless, careful evaluation of in vitro and in vivo results are also needed to estimate the risk factors and possible outcomes in case of human exposure (parallelogram approach by Xing et al., 2006) [32,33].

\section{Materials and Methods}

\subsection{Preparation and Characterization of Dry Plantago lanceolata Leaf Methanolic Extract}

P. lanceolata leaves of pharmacopoeial quality were of commercial origin. It was reduced to a fine powder prior to further work. The powder was extracted with $\mathrm{MeOH}$ under reflux (100 g Dry Weight DW-400 $\mathrm{mL} \mathrm{MeOH}$ ) for $30 \mathrm{~min}$, filtered, and evaporated to dryness in a rotary evaporator. Subsequently, the plant extract was defatted with hexane $(3 \times 50 \mathrm{~mL})$ and dried again. 100 g plant drug yielded $25.2 \mathrm{~g}$ dry extract.

$10 \mathrm{mg} / \mathrm{mL}$ solutions of the dry extract were prepared with $\mathrm{MeOH}$ and diluted 100 to 250-fold for analysis. Authentic standards of catalpol, aucubin, and acteoside were used as standards to construct the calibration curves in the concentration range $0.2-20 \mu \mathrm{g} \mathrm{mL}^{-1}(\mathrm{MeOH})$. The quantification of natural products by LC-MS was run on a Thermo Accela HPLC attached to a Thermo LTQ XL Linear Ion Trap MS (column: kinetex XB- $\mathrm{C}_{18} 100 \mathrm{~mm} \times 2.1 \mathrm{~mm} \times 2.6 \mu \mathrm{m}$ ). Gradient components were A, water with $0.1 \%(v / v)$ formic acid; $B$, acetonitrile with $0.1 \%(v / v)$ formic acid. The time programme was $5 \% \mathrm{~B}$ : 0-1 min, 5-20\% B: 1-5 min, 20-60\% B: 5-9 min, 60-100\%: 9-11 min; 100\% B: $11-13 \mathrm{~min} ; 100-5 \%$ B: 13-15 min, 5\% B: 15-17.5 min. Flow rate was $250 \mu \mathrm{L} / \mathrm{min}$. Injection volume was $1 \mu \mathrm{L}$. Iridoids were detected in positive mode, and acteoside was detected in negative ion mode. Electrospray ionisation (ESI) parameters were as follows: heater temperature, unheated; sheath gas, $\mathrm{N}_{2}$; flow rate, 8 arbitrary units (arb); aux gas flow rate, 0 arb; spray voltage, $5 \mathrm{kV}$; capillary temperature, $275^{\circ} \mathrm{C}$. Capillary voltage was $7 \mathrm{~V}$ and $-35 \mathrm{~V}$ in positive ion mode and negative ion mode, respectively. Calibration curves of $0.2-20 \mu \mathrm{g} \mathrm{mL}^{-1}$ were used, and pure compounds were dissolved in $\mathrm{MeOH}$.

\subsection{Preparation and Characterization of Dry Plantago lanceolata Leaf Methanolic Extract}

P. lanceolata leaves of pharmacopoeial quality were of commercial origin. It was reduced to a fine powder prior to further work. The powder was extracted with $\mathrm{MeOH}$ under reflux $(100 \mathrm{~g} \mathrm{DW}-400 \mathrm{~mL}$ $\mathrm{MeOH}$ ) for $30 \mathrm{~min}$, filtered, and evaporated to dryness in a rotary evaporator. Subsequently, the plant extract was defatted with hexane $(3 \times 50 \mathrm{~mL})$ and dried again. $100 \mathrm{~g}$ plant drug yielded $25.2 \mathrm{~g}$ dry extract.

$10 \mathrm{mg} / \mathrm{mL}$ solutions of the dry extract were prepared with $\mathrm{MeOH}$ and diluted 100 to 250-fold for analysis. Authentic standards of catalpol, aucubin, and acteoside were used as standards to construct the calibration curves in the concentration range $0.2-20 \mu \mathrm{g} \mathrm{mL}-1(\mathrm{MeOH})$.

\subsection{Formulation and Evaluation of Self-Nano-Emulsifying Drug Delivery Systems}

Different self-emulsifying combinations have been formulated by the water and oil dilution method with various previously tested tensides and co-tensides [15]. The compositions are listed in Table 1. Tenside components were mixed at $37^{\circ} \mathrm{C}$ by Schott Tritronic dispenser (SI Analytical, Mainz, Germany) combined with Radelkis OP-912 magnetic stirrer (Radelkis, Budapest, Hungary). The applied concentrations of cytostatic drugs were dissolved in the systems at room temperature by 
permanent agitation. To evaluate any signs of phase separation, the mixtures were equilibrated for 24 h. An Erweka DT800 rotating paddle apparatus (Erweka GmbH, Heusenstamm, Germany) was used to evaluate the efficiency of self-emulsification of different mixtures. One gram of each mixture was added to $200 \mathrm{~mL}$ of distilled water with gentle agitation condition provided by a rotating paddle at $70 \mathrm{rpm}$ and at a temperature of $37^{\circ} \mathrm{C}$. The process of self-emulsification was visually monitored for the rate of emulsification and for the appearance of the produced emulsions. The visual properties registered against the increment of the applied surfactant component in Ternary triangular diagrams. Plotting points of preferential combinations were selected according to cartesian coordinate calculation.

\subsection{Determination of Droplet Size of PL-SNEDDS}

The diameter of dispersed phase was investigated by a Cumulant dynamic light scattering (DLS) device (Malvern, Worchestershire, UK). The correlation of intensity function has been analyzed to obtain the diffusion coefficient. The measurements have been performed by a Brookhaven Fotometer Apparatus (Brookhaven, Upton, NY, USA). The operation temperature was adjusted to $25{ }^{\circ} \mathrm{C}$, the laser detection angle to 90 degrees, Lambda to $533 \mathrm{~nm}$, and the index to 1.334 by Particle Size Program 3.1 (Malvern, Worchestershire, UK). Diameters of dispersed droplets according to the diffusion coefficient have been evaluated automatically by the computer program.

\subsection{Cell Culturing}

Caco-2 (human adenocarcinoma cancer cells) was obtained from the European Collection of Cell Cultures (ECACC, Public Health England, Salisbury, UK). Cells were grown in plastic cell culture flasks in Dulbecco's Modified Eagle's Medium (Sigma-Aldrich Buchs, St. Gallen, Switzerland), supplemented with $3.7 \mathrm{~g} / \mathrm{L} \mathrm{NaHCO}_{3}, 10 \%(v / v)$ heat-inactivated fetal bovine serum (FBS), $1 \%(v / v)$ non-essential amino acids solution, $1 \%(v / v)$ l-glutamine, $100 \mathrm{IU} / \mathrm{mL}$ penicillin, and $100 \mathrm{IU} / \mathrm{mL}$ streptomycin at $37^{\circ} \mathrm{C}$ in an atmosphere of $5 \% \mathrm{CO}_{2}$. The cells were routinely maintained by regular passaging. For cytotoxic and transport experiments, cells were used between passage numbers 20 and 40 . The culture media was replaced with fresh media in every $72 \mathrm{~h}$ [33].

\subsection{In Vitro Cell Viability Assay}

To exclude any toxic effect of the blank SNEDDS and PL-SNEDDS on Caco-2 cells, MTT cell viability test was used [34]. Cells were seeded on flat bottom 96-well tissue culture plates at a density of $10^{4}$ cells/well and allowed to grow in a $\mathrm{CO}_{2}$ incubator at $37^{\circ} \mathrm{C}$ for 4 days. For these studies, the culture medium was removed, surfactant or SNEDDS solutions were added, and the cells were incubated for a further $30 \mathrm{~min}$. After removing the samples, another 3-h-incubation in a medium containing MTT at the concentration of $0.5 \mathrm{mg} / \mathrm{mL}$ followed. The dark blue formazan crystals were dissolved in acidic isopropanol (isopropanol:1.0 M hydrochloric acid $=25: 1$ ). The absorbance was measured at $570 \mathrm{~nm}$ against a $690 \mathrm{~nm}$ reference with FLUOstar OPTIMA Microplate Reader (BMG LABTECH, Offenburg, Germany). Cell viability was expressed as the percentage of the untreated control [35].

\subsection{DPPH Radical Scavenging Activity of SNEDDS-PL Samples}

Each sample (PL-Composition 1-3, 5-8, Composition 1-3, 5-8, PL-E) was reacted with the stable DPPH radical in ethanol (96\%). The reaction mixture consisted of adding $100 \mu \mathrm{L}$ of sample, $900 \mu \mathrm{L}$ of absolute ethanol, and $2 \mathrm{~mL}$ of DPPH radical solution $(0.06 \mathrm{mM})$ in absolute ethanol. The mixtures incubated for $30 \mathrm{~min}$. When DPPH reacted with an antioxidant compound, which can donate hydrogen, it was reduced. The reaction resulted in color change from deep violet to light yellow. Quantitative measurement of remaining DPPH was carried out with an UV-spectrophotometer (Shimadzu Spectrophotometer, Tokyo, Japan) at a wavelength of $\lambda=517 \mathrm{~nm}$. In case of photometric determination mixtures, absolute ethanol served as background. The control solutions were the same compositions without $P$. lanceolata extract. To demonstrate the improved antioxidant effect of 
combinations, blank P. lanceolata extract $(10 \mathrm{mg} / \mathrm{mL})$ was applied as well. The scavenging activity percentage (AA\% = Antioxidant Activity) was determined according to Mensor et al. [35].

$$
\mathrm{AA} \%=100-\left[\left(\left(\mathrm{Abs}_{\text {sample }}-\mathrm{Abs}_{\text {blank }}\right) \times 100\right) / \mathrm{Abs}_{\text {control }}\right] .
$$

\subsection{In Vitro Dissolution Test}

In vitro dissolution test of PL-Compositions based on the determination of DPPH Radical Scavenging Activity of $P$. lanceolata extract.

In vitro drug release from PL-SNEDDS were conducted according to FDA-recommended dissolution methods in $\mathrm{pH}=6.8$. The dissolution condition was $500 \mathrm{~mL}$ of $\mathrm{pH} 6.8$ phosphate buffer at a paddle speed of $75 \mathrm{rpm}$. Aliquots of $3 \mathrm{~mL}$ were withdrawn and filtered using $0.45 \mu \mathrm{m}$ filter at predetermined time intervals of 5, 10, 15, 30,60 min. The volume removed from each solution was replaced immediately with fresh dissolution medium. The determination of diffused P. lanceolata extract based on the DPPH Radical Scavenging Activity (see below).

\subsection{Animals and Experimental Groups}

Swiss male mice (22 $\pm 3 \mathrm{~g})$, supplied by the Animal House of the School of Medicine, Faculty of Pharmacy, Ahvaz Jundishapur University of Medical Sciences, Ahvaz, Iran, (Ethical approval number is IR.AJUMS.REC. 1394.139) were used. The animals were maintained at a $12 \mathrm{~h} \mathrm{light/dark} \mathrm{cycle,} \mathrm{at}$ constant temperature, with access to food and tap water ad libitum. All experimental procedures were approved by the Ethical Committee of Ahvaz Jandishapur University of Medical Sciences, Faculty of Pharmacy, Ahvaz, Iran. During the experiments, animals were processed according to the suggested international ethical guidelines for the care of laboratory animals. Fifty four animals were used for hepatic function markers investigations and forty-eight animals for ear oedema tests. For the first experiment, the mice were divided into nine groups (one control and eight groups for SMEDDS-PL investigation), for the second experiment, eight mice groups were composed (one positive and one negative control and six groups for SMEDDS-PL investigation). The extracts ( $150 \mathrm{mg} / \mathrm{kg} /$ day) were administered by gastric gavage ( $100 \mu \mathrm{L}$ three times daily). The controls were given the same volume as in the test group.

The mice were anaesthetized on the final day of experiments, and blood was collected from venae cavae before mice were euthanized by cervical dislocation.

\subsection{Preparation of Blood Plasma}

The collected blood was placed in heparinized tubes and centrifuged for $15 \mathrm{~min}$ at $2000 \mathrm{rpm}$ in order to obtain plasma samples, which were used immediately to determine ALT and AST activities.

\subsection{Assay of Plasmatic Markers}

The plasmatic activities of aspartate aminotransferase (AST) and alanine aminotransferase (ALT) were evaluated by the spectrophotometric method using commercially available kits (Roche reagents, Meylan, France), according to the manufacturer's indication.

\subsection{Dimethyl-Benzene-Induced Inflammation Model}

Anasthesia was induced by thiopental in an amount of $50 \mathrm{mg} / \mathrm{kg}$ intraperitoneally (i.p.), repeated as required. The posterior area of the right ear was then injected with $3 \mathrm{~m} / \mathrm{m} \%$ dimethyl-benzene solution. This treatment was applied $30 \mathrm{~min}$ after the oral gavage. Thus, the oral administration of SNEDDS-PL was performed firstly, and the induction of inflammation was carried out secondly. 


\subsection{Measurement of Ear Oedema}

Ear thickness was measured by a micrometer caliper (Oxford Precision, Leicester, UK), with $0.1 \mathrm{~mm}$ accuracy before dimethyl-benzene treatment and $15 \mathrm{~min}$ after the first dimethyl-benzene application, then by each hour during a $6 \mathrm{~h}$ period after each $3 \mathrm{~m} / \mathrm{m} \%$ dimethyl-benzene treatment according to Ujhelyi J., et al. [21]. SNEDDS-PL treatment was performed $30 \mathrm{~min}$ before starting time of ear edema induction. Data were expressed in micrometers.

\subsection{Statistical Analysis}

Data were handled and analyzed using Microsoft Excel 2013 and SigmaStat 4.0 (version 3.1; SPSS, Chicago, IL, USA, 2015), and herein presented as means \pm SD. Comparison of results of MTT cell viability assays, hepatic function markers (AST, ALT), free radical scavenging activity test, in vitro dissolution test, and ear edema test was performed with one-way ANOVA and repeated-measures ANOVA followed by Tukey or Dunnett post testing. Difference of means was regarded as significant in case of $p<0.05$. All experiments were carried out in quintuplicates and repeated at least five times $(n=5)$.

\section{Conclusions}

Finally, it can be concluded that PL-SNEDDS compositions have a high potential to improve the stability of APIs of Plantago lanceolata extract and also can improve the antioxidant and anti-inflammatory effect of natural compounds. These samples could be a feasible alternative for medical purposes.

Nevertheless, in vitro cytocompatibility and in vivo animal studies indicated that more tests are needed to estimate the overall toxicity profile of PL-SNEDDS compositions.

Acknowledgments: This work was supported by the EFOP-3.4.3.-16-2016-0021 and EFOP-3.6.1--16-2016-00022 projects.

Author Contributions: Ildikó Bácskay and Miklós Vecsernyés designed the experiment. Azin Kalantari, Dániel Nemes, Dóra Kósa, Pálma Fehér, and Zoltán Ujhelyi made the experiments. Ferenc Fenyvesi, Ildikó Bácskay, and Judit Váradi evaluated the data. Sándor Gonda and Gábor Vasas characterized the plaintain and prepared the extracts. Ákos Kuki managed the DLS experiments. Azin Kalantari and Rudolf Gesztelyi made the statistical analysis. Anayatollah Salimi contributed to the animal experiment. All authors read and approved the final manuscript.

Conflicts of Interest: The authors declare no conflict of interest.

\section{References}

1. Goncalves, S.; Romano, A. The medicinal potential of plants form the genus Plantago (Plantaginaceae). Ind. Crops Prod. 2016, 82, 213-226. [CrossRef]

2. Chiou, W.F.; Lin, L.C.; Chen, C.F. Acteoside protects endothelial cells against free radical-induced oxidative stress. J. Pharm. Pharmacol. 2004, 56, 743. [CrossRef] [PubMed]

3. Lee, J.Y.; Woo, E.R.; Kang, K.W. Inhibition of lipopolysaccharide-inducible nitric oxide synthase expression by acteoside through blocking of AP-1 activation. J. Ethnopharmacol. 2005, 97, 561. [CrossRef] [PubMed]

4. Xiong, L.; Mao, S.; Lu, B.; Yang, J.; Zhou, F.; Hu, Y.; Jiang, Y.; Shen, C.; Zhao, Y. Osmathus fragrans Flower Extract and Acteoside Protect Agaianst d-Galactose-Induced Aging in an ICR Mouse Model. J. Med. Food 2016, 19, 54-61. [CrossRef] [PubMed]

5. Yang, J.; Yan, Y.; Liu, H.; Wang, J.; Hu, J. Protective effects of acteoside against X-ray induced damage in human skin fibroblast. Mol. Med. Rep. 2015, 12, 2301-2306. [CrossRef] [PubMed]

6. Kovac, I.; Durkac, J.; Holly, M.; Jakubcova, K.; Perzelova, V.; Mucaji, P.; Svajdlenka, E.; Sabol, F.; Legath, J.; Belák, J.; et al. Plantago lanceolata L. water extract induces transition of fibroblasts into myofibroblasts and increases tensile strength of healing skin wounds. J. Pharm. Pharmacol. 2014, 67, 117-125. [CrossRef] [PubMed] 
7. Gonda, S.; Nguyen, N.M.; Batta, G.; Gyémánt, G.; Máthé, C.; Vasas, G. Determination of phenylethanoid glycosides and iridoid glycosides from therapeutically used Plantago species by CE-MEKC. Electrophoresis 2013, 34, 2577-2584. [CrossRef] [PubMed]

8. He, J.; Hu, X.P.; Zeng, Y.; Li, Y.; Wu, H.; Qiu, R.; Ma, W.; Li, T.; Li, C.; He, Z. Advanced research on acteoside for chemistry and bioactivities. J. Asian Nat. Prod. Res. 2011, 13, 449-464. [CrossRef] [PubMed]

9. Isacchi, B.; Bergonzi, M.C.; Iacopi, R.; Ghelardini, C.; Galeotti, N.; Bilia, A.R. Liposomal Formulation to increase Stability and Prolong Antineuropathic Activity of Verbascoside. Planta Med. 2016, 83, 412-419. [CrossRef] [PubMed]

10. Vertuani, S.; Beghell, E.; Scalambra, E.; Malisardi, G.; Copetti, S.; Dal Toso, R.; Baldisserotto, A.; Manfredini, S. Activity and Stability Studies of Verbascoside, a Novel Antioxidant, in Dermo-Cosmetic and Pharmaceutical Topical Formulations. Molecules 2011, 15, 7068-7080. [CrossRef] [PubMed]

11. Zhang, L.; Zhang, I.; Zhang, M.; Pang, Y.; Li, Z.; Zhao, A.; Feng, J. Self-emulsifying drug delivery system and the applications in herbal drug. Drug Deliv. 2013, 22, 475-486. [CrossRef] [PubMed]

12. Ma, H.; Zhao, Q.; Wang, Y.; Guo, T.; An, Y.; Shi, G. Design and evaluation of self-emulsifying drugdelivery systems of Rhizoma corydalis decumbentis extracts. Drug Dev. Ind. Pharm. 2012, 38, 1200-1206. [CrossRef] [PubMed]

13. Eid, A.M.; El-Enshasy, H.A.; Aziz, R.; Elmarzug, N.A. The preparation and evaluation of self-nanoemulsifying system containing Swietenia oil and an examination of its anti-inflammatory effects. Int. J. Nanomed. 2014, 9, 4685-4695.

14. European Pharmacopoiea 9th Edition. Available online: https://www.edqm.eu/en/europeanpharmacopoeia-9th-edition (accessed on 29 June 2017).

15. Ujhelyi, Z.; Fenyvesi, F.; Váradi, J.; Fehér, P.; Kiss, T.; Veszelka, S.; Deli, M.A.; Vecsernyés, M.; Bácskay, I. Evaluation of cytotoxicity of surfactants used in self-micro emulsifying drug delivery systems and their effects on paracellular transport in Caco-2 cell monolayer. Eur. J. Pharm. Sci. 2012, 47, 564-573. [CrossRef] [PubMed]

16. Brand-Williams, W.; Cuvelier, M.E.; Berset, C. Use of a free radical method to evaluate antioxidant activity. LWT_Food Sci. Technol. 1995, 28, 25-30. [CrossRef]

17. Grigore, A.; Colceru-Mihul, S.; Litescu, S.; Pantelli, M.; Rasit, I. Correlation between polyphenol content and anti-inflmammatory activity of Verbascum phlomoides (Mullein). Pharm. Biol. 2013, 51, 925-929. [CrossRef] [PubMed]

18. Sinico, C.; Caddeo, C.; Valenti, D.; Fadda, A.M.; Bilia, A.R.; Vincieri, F.F. Liposomes as carriers for verbascoside: Stability and skin permeation. J. Liposome Res. 2008, 18, 83-90. [CrossRef] [PubMed]

19. Choudhrey, Q.N.; Kim, M.J.; Kim, T.G.; Pan, J.H.; Kim, J.H.; Park, S.J.; Lee, J.H.; Kim, Y.J. Saponin-Based Nanoemulsification Improves the Antioxidant Properties of Vitamin A and E in AML-12 cells. Int. J. Mol. Sci. 2016, 17, 1406. [CrossRef] [PubMed]

20. Mello, J.C.; Gonzales, M.V.D.; Moraes, V.W.R.; Prieto, T.; Nascimento, O.R.; Rodrigues, T. Protective Effect of Plantago major Extract against t-BOOH-Induced Mitochondrial Oxidative Damage and Cytotoxicity. Molecules 2015, 20, 17747-177759. [CrossRef] [PubMed]

21. Ujhelyi, J.; Ujhelyi, Z.; Szalai, A.; László, J.F.; Cayasso, M.; Vecsernyés, M.; Pórszász, R. Analgesic and anti-inflammatory effectiveness of sitagliptin and vitagliptin in mice. Regul. Pept. 2014. [CrossRef]

22. Fakhrudin, N.; Astuti, E.D.; Sulistyawati, R.; Santosa, D.; Susandarini, R.; Nurrochmad, A.; Wahyuono, S. $n$-Hexane Insoluble Fraction of Plantago lanceolate Exerts Anti-Inflammatory Activity in Mice by Inhibiting Cyclooxygenase-2 and Reducing Chemokines Levels. Sci. Pharm. 2017, 85, 12. [CrossRef] [PubMed]

23. Li, W.; Shaoling, Y.; Wang, Z.; Chen, S.; Xin, S.; Xie, J.; Zhao, C. Self-nanoemulsifying drug delivery system of persimmon leaf extract: Optimization and bioavailability studies. Int. J. Pharm. 2011, 420, 161-171. [CrossRef] [PubMed]

24. Parikh, A.; Kathawala, K.; Tan, C.C.; Garg, S.; Zhou, X.F. Lipid-based nanosystem of edaravone: Development, optimization, characterization and in vitro/in vivo evaluation. Drug Deliv. 2017, 24, 962-978. [CrossRef] [PubMed]

25. Pouton, C.W. Lipid formulations for oral administration of drugs: Non-emulsifying, self-emulsifying and 'self-microemulsifying' drug delivery systems. Eur. J. Pharm. Sci. 2000, 11 (Suppl. 2), 93-98. [CrossRef]

26. Naguib, S.S.; Hathout, R.M.; Mansour, S. Optimizing novel penetration enhancing hybridized vesicles for augmenting the in vivo effect of an anti-glaucoma drug. Drug Deliv. 2017, 24, 99-108. [CrossRef] [PubMed] 
27. Powell, K.C.; Damitz, R.; Chauhan, A. Relating emulsion stability to interfacial properties for pharmaceutical emulsions stabilized by Pluronic F68 surfactant. Int. J. Pharm. 2017, 521, 8-18. [CrossRef] [PubMed]

28. Ujhelyi, Z.; Róka, E.; Fenyvesi, F.; Fehér, P.; Váradi, J.; Réti-Nagy, K.; Vecsernyés, M.; Bácskay, I. Assessment of the hemolytic activity and cytotoxicity of different PEG-based solubilizing agents. Pharmazie 2013, 68, 383-384. [PubMed]

29. Sandri, G.; Bonferoni, M.C.; Rossi, S.; Ferri, F.; Gibin, S.; Zambito, Y.; Di Colo, G.; Caramella, C. Nanoparticles Based on N-trimethylchitosan: Evaluation of absorption properties using in vitro (Caco-2 cells) and ex vivo (excised rat jejunum) models. Eur. J. Pharm. Biopharm. 2007, 65, 68-77. [CrossRef] [PubMed]

30. Bigansoli, E.; Cavenaghi, L.A.; Rossi, R.; Brunati, M.C.; Nolli, M.L. Use of a Caco-2 cell culture model for the characterization of intestinal absorption of antibiotics. Farmaco 1999, 54, 594-599. [CrossRef]

31. Fotakis, G.; Timbrell, J.A. In vitro cytotoxicity assays. Comparison of LDH, neutral red, MTT and protein assay in hepatoma cell lines following exposure to cadmium chloride. Toxicol. Lett. 2006, 160, 171-177. [CrossRef] [PubMed]

32. Xing, J.Z.; Zhu, L.; Gabos, S.; Xie, L. Microelectronic cell sensor assay for detection of cytotoxicity and prediction of acute toxicity. Toxicol. Vitro 2006, 20, 995-1004. [CrossRef] [PubMed]

33. Palamakula, A.; Khan, M.A. Evaluation of cytotoxicity of oils used in coenzyme Q10 Self-emulsifying Drug Delivery Systems (SEDDS). Int. J. Pharm. 2004, 273, 63-73. [CrossRef] [PubMed]

34. Gursoy, N.; Garrigue, J.S.; Razafindratsita, A.; Lambert, G.; Benita, S. Excipient effects on in vitro cytotoxicity of a novel paclitaxel self-emulsifying drug delivery system. J. Pharm. Sci. 2003, 92, 2411-2418. [CrossRef] [PubMed]

35. Mensor, L.L.; Menezes, F.S.; Leitao, G.G.; Reis, A.S.; dos Santos, T.C.; Coube, C.S.; Leitão, S.G. Screening of Brazilian plant extracts for antioxidant activity by the use of DPPH free radical method. Phytother. Res. 2001, 15, 127-130. [CrossRef] [PubMed]

Sample Availability: Plantago lanceolate extract is available from the authors.

(C) 2017 by the authors. Licensee MDPI, Basel, Switzerland. This article is an open access article distributed under the terms and conditions of the Creative Commons Attribution (CC BY) license (http://creativecommons.org/licenses/by/4.0/). 